\title{
COMPARISON OF DIFFERENT CLASSIFICATION TECHNIQUES TO IDENTIFY COCONUT GROWING AREAS IN KOZIKHODE DISTRICT, KERALA
}

\author{
Niti Singh, Shreya Roy, Pradeep Kumar, M.M Kimothi and S. Mamatha \\ Mahalanobis National Crop Forecast Centre, DAC\&FW, Pusa, New Delhi-110012, India- (niti.geoinfo, royshreya406)@gmail.com, \\ pradeep.kumar82@gov.in,drmmkimothi@gmail.com, mamatha.ncfe@nic.in
}

\author{
Commission III, WG III/10
}

KEY WORDS: Coconut, Sentinel-2A, NDVI, MXL, ISODATA, Random Forest, CHAMAN

\begin{abstract}
:
This study was envisaged to map the coconut growing areas in Kerala state of India, using multidate NDVI obtained from sentinel 2A MSI data, having spatial resolution as $10 \mathrm{~m}$. 95\% Cloud free satellite images were taken for classification and date of pass considered for the study were $16^{\text {th }}$ February, 2017 and $18^{\text {th }}$ December, 2017 for Kozhikode district of Kerala. In this study biowindow of coconut plantation was identified using NDVI images of two dates. It was observed that interclass variations were more prominent in February image. Forest, dense and moderately dense coconut plantations have significantly different NDVI values in February image whereas in December image all three features have similar values. Hence, February image was classified using three classification methods i.e. ISODATA, maximum likelihood and random forest classification to assess which method is better to distinguish coconut plantation from other classes. Random Forest classification technique was found to be more accurate in identifying coconut plantation. Area was also estimated for Kozhikode district and compared with the government statistics. Google Earth was taken as reference to identify coconut plantation as it has a unique star shaped canopy, which is clearly visible in highresolution imagery.
\end{abstract}

\section{INTRODUCTION}

The Coconut Palm (Cocos nucifera L.) is the primary member of the family Arecaceae (palm family). It is an important horticultural tree crop of humid tropics. Coconut is a versatile fruit with many uses, hence, it occupies a unique position in the socio-economic structure of India and it is intimately related to the prosperity of a vast multitude of small and marginal farmers especially along the coastal states of this country (Mandal et.al, 2011). Kerala was considered for this study because it contributes around $37 \%$ of the total coconut areas of India. According to statistics Kozhikode district has largest area around $16 \%$ share of total area in Kerala followed by Thrissur, Malappuram, Kannur, Thiruvananthapuram, Kollam, Kasaragod and Alappuzha which in total contribute around $83.3 \%$ of total coconut area of Kerala (Horticulture Area Production Information System, HAPIS, portal). Along with coconut, banana, mango, jackfruit, cashew and spices like pepper, nutmeg and cardamom are important crops in Kerala. Hence, monitoring of all these crops is essential to understand the real production and yield of these crops.

The modern tool of remote sensing is a better option to understand the trend of growth of all these crops, as it has a capability to provide real-time data with synoptic and repetitive coverage, which gives significant advantage over traditional methods (Parthasarthy et.al. 2003). Many remote sensing-based studies have been carried out for monitoring coconut plantation. Geo Eye $(41 \mathrm{~cm})$ of March 2012-June 2014 was used to map coconut-growing areas in Tamil Nadu and Google Earth was used as reference (Kannan et.al. 2017). In one study, LISS III (23.5m spatial resolution) March image was used to identify coconut plantations in Kasaragod district Kerala (Parthasarthy et al., 2003). Coconut has a distinct tone (lighter red to pinkish) and can be easily separated using maximum likelihood classification from other crops like rubber, cashew etc. Landsat ETM+ was used to identify Sago palms in Philippines using
NDVI and maximum likelihood classification with modest accuracy (Santillan et al. 2012). Also urban tree species were mapped using very high Resolution Satellite imagery and pixel and object based classification were compared (Agarwal et.al. 2013). Advance classification techniques may improve the mapping of coconut plantation. A study with Object based classification was used to classify the coconut plantation using Cartosat-1 PAN and LISS-IV data in Krishna district, Andhra Pradesh (Sahay et al, 2017). Also, inventory of horticultural was prepared using high resolution with Object Oriented classification. (Hebbar et al, 2014).

Random Forest classification is an advanced technique which is used these days for ecological mapping. A study was carried for forest classification in Victoria, Australia which evaluates the utility and performance of a Machine Learning Decision tree classification technique- Random Forest (Mellor et.al. 2012). This technique was also used in Tree Species Classification using High Spatial Resolution 8-Band WorldView-2 Satellite Data. Hence, it would help in identifying Coconut classification more precisely (Immitzer et al., 2012).

This study was carried out as part of the CHAMAN (Coordinated Horticulture Assessment and Management using Geo-informatics) project, which envisages using high resolution remote sensing data for improving inventory of horticultural crops. This paper mainly describes about the classification techniques for coconut area identification in Kozhikode district.

\section{MATERIALS AND METHODS}

\subsection{Study Area}

The study was done for the Kozhikode district in Kerala State of India (Figure 1). It is located around geographical location of $11.5817^{\circ} \mathrm{N}$ and $75.7803^{\circ} \mathrm{E}$, on the South-West coast of India. Topographically the district has three distinct regions - the sandy coastal belt, the rocky highlands formed by the hilly

*Corresponding author 
portions of the Western Ghats and lateritic midland. Soils of the districts are alluvial soil, laterite soil and forest loam. Alluvial soil is seen mostly along coastal plain and valley. The minimum temperature ranges between 22 and $25^{\circ} \mathrm{C}$ and maximum between 28.2 and $32.9^{\circ} \mathrm{C}$. The temperature reaches its peak in the month of April and attains minimum in January (Source: District Survey Report on Minor Minerals 2016, Kozhikode District).

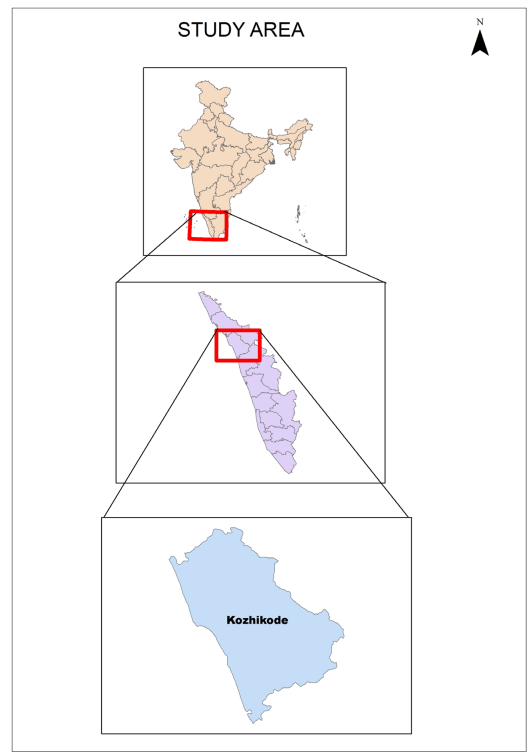

Figure 1. Study Area

\subsection{Data Used}

High resolution Sentinel-2A MSI (10m spatial resolution) cloud free data was used for dates of 16 February 2017 and 18 December 2017. Only cloud free images were considered (. Table 1).

\begin{tabular}{cccc}
\hline Satellite & Path/Row & Date & Bands \\
\hline Sentinel 2A & T43 PEN & 16 Feb 2017 & 3.4 .8 \\
Sentinel 2A & T43 PEN & 18 Dec 2017 & $3,4,8$ \\
\hline
\end{tabular}

Table 1: Satellite data specifications

\subsection{Methodology}

2.3.1 Satellite data pre-processing: Sentinel 2A MSI Data were downloaded, layer-stacked, and subset was prepared using district boundary of Kozhikode.

\subsubsection{Normalized Differential Vegetation Index (NDVI)} generation: NDVI calculation involves the reflectance in red and near-infrared bands of electromagnetic spectrum which is sensitive to vegetation cover, biomass, crop condition and density (Baruth et.al. 2008).

NDVI (Rouse et al., 1974) images were generated from the reflectance images using the equation given below:

NDVI $=(\rho \mathbf{N I R}-\rho \mathbf{R e d}) /(\rho \mathbf{N I R}+\rho \mathbf{R e d})$

where $\rho$ is TOA reflectance.
2.3.2 Classification: Three types of classification techniques were used. Those are ISODATA clustering, maximum likelihood classification and Random Forest classification. Classifiers were employed on the data of 16 February 2017. Last two methods involved selection of training sets for each land cover class. Classes considered were Coconut (Moderately Dense canopy and Dense canopy), Forest, Water Bodies and Non- Vegetation Classes (Built-up, Barren land, Wasteland) etc.

2.3.3 Accuracy Assessment: Overall accuracy for all three methods was carried out in order to compare the outputs and find out which method was best. Reference data was taken from Google earth as coconut plantation shows star shaped canopy on the top which differentiate it from other vegetation (figure 3)

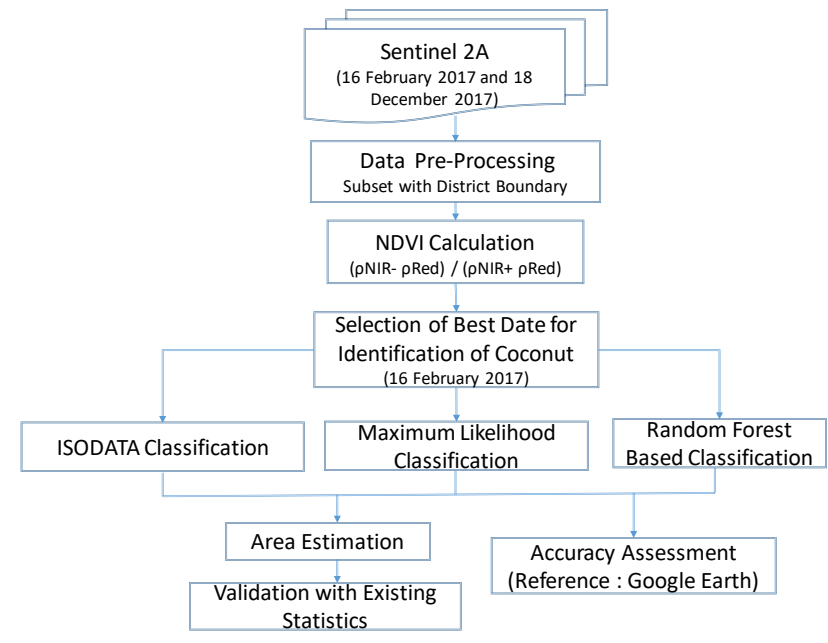

Figure 2. Methodology Flowchart

\section{RESULT AND DISCUSSION}

\subsection{Two Date NDVI Comparison}

To identify the optimum bio-window for coconut, NDVI values of two date images were compared.

NDVI values comparison showed that interclass variations were more prominent in February image as forest, dense and moderately dense coconut plantations have significantly different NDVI values in February image whereas in December image all three classes have similar values (Figure 3). Reason behind the low NDVI value of coconut canopy is due to due to low rainfall during January and February months (Ananthakrishnan et al., 1988). It is found that the soil moisture is low during dry season and high during the rainy season (Roxy et.al. 2010). Two dates images along with Google earth view are shown in figure 4. 


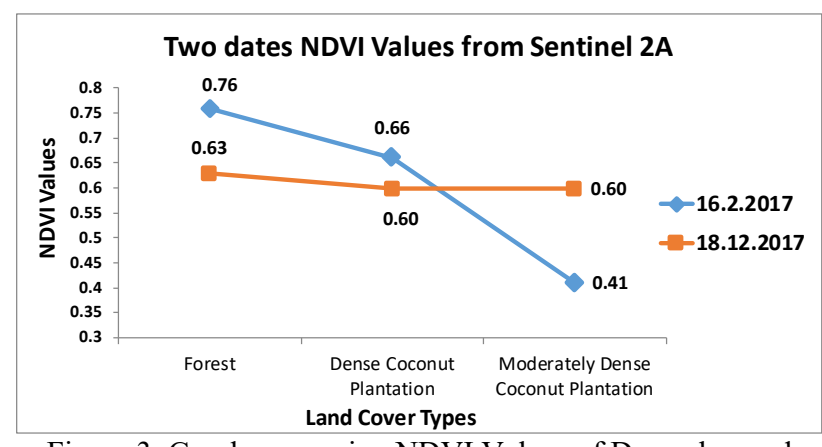

Figure 3. Graph comparing NDVI Values of December and February Images.

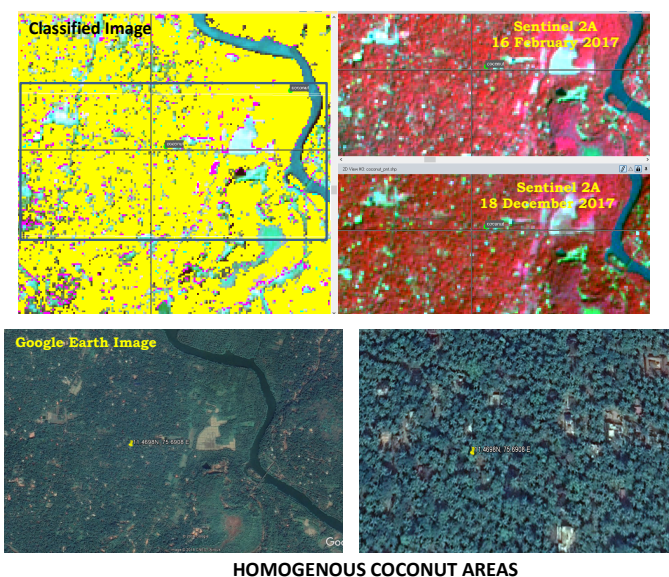

Figure 4: Two Date Sentinel 2A MSI Image-Part of Kozhikode District compared with google earth.

\subsection{Classification Output}

To classify coconut plantation February image was used, as interclass variation was prominent at that time. After assessing accuracy for individual output, it was observed that advance classifier i.e. random forest could separate out coconut plantation from forest more clearly. Classification accuracy for each technique is given in table 2. Results for each classification are shown below in figure 5 .

\begin{tabular}{ll}
\hline Classification Technique & Overall accuracy (\%) \\
\hline ISODATA clustering & 67.01 \\
Maximum Likelihood & 70.34 \\
Classification & \\
Random Forest Classification & 75.89 \\
\hline \multicolumn{2}{l}{ Table 2: Overall accuracy for all three classification techniques. }
\end{tabular}

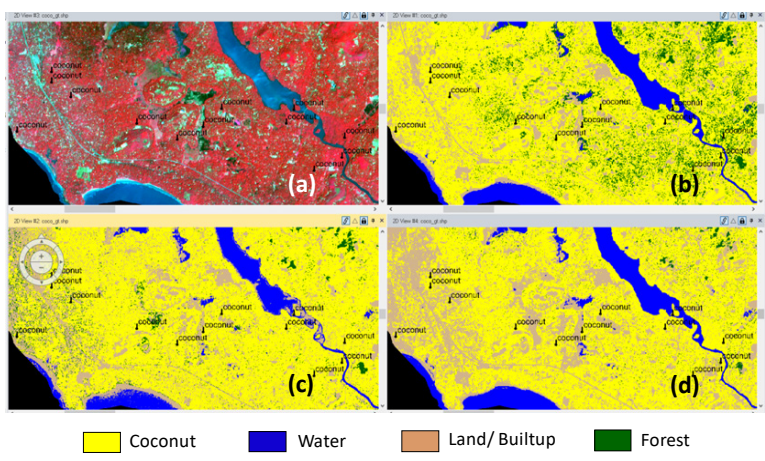

Figure 5. (a) Sentinel 2A Data -16 February 2017, Classification Output for (b) ISODATA, (c) MXL and (d) Random Forest Classification

\subsection{Area Estimation:}

Coconut Area was estimated from all the three classification techniques. It was found that percentage deviation of area estimated using Random Forest was very less from existing statistics (HAPIS portal) for Kozhikode district. Area and deviation is shown in Table 3.

\begin{tabular}{lcc}
\hline \multicolumn{1}{c}{ Technique } & Area Estimated & $\begin{array}{c}\text { \%Deviation } \\
\text { form DAC } \\
\text { Average }\end{array}$ \\
\hline $\begin{array}{l}\text { Government Estimate } \\
\text { (4 Year Average) }\end{array}$ & 123.61 & -- \\
Random Forest & 124.36 & 0.61 \\
MXL & 138.37 & 11.94 \\
ISODATA & 139.86 & 13.15
\end{tabular}

Table 3: Area estimated and Deviation with existing Statistical data

\section{CONCLUSION}

In Kerala most of the crop is plantation crop. Hence, it is a major issue to identify coconut vis-a-vis other plantation crops like rubber, spices etc. Kozhikode district, due to its physiographical conditions, has healthy vegetation with forest regions. Dense Coconut regions may mix with forest and other vegetations in low resolution satellite imagery. Hence, Sentinel $2 \mathrm{~A}$ data was taken to reduce interclass mixing.

To identify the bio-window two date images were taken and NDVI values of both were compared. February data was found to be more reliable in classifying coconut plantation in Kozhikode District. This may be because of low rainfall and low soil moisture conditions during dry season (February to May) due to which wilting of leaves occur, which may be the reason of lower NDVI values of coconut plantation as compared to forests.

Also, Machine learning algorithm i.e. Random Forest classification output was found to be more efficient in terms of area estimation and accuracy assessment, than conventional ISODATA and maximum likelihood classification techniques.

\section{ACKNOWLEDGEMENT}

The study was conducted under the CHAMAN (Coordinated Horticulture Assessment and Management using geoiNformatics) project under the Mission for Integrated Development of Horticulture (MIDH) of Department of Agriculture, Cooperation and Farmer's Welfare. Authors are grateful to Dr. S. S. Ray, Director, MNCFC for his constant encourage, technical guidance for the work and review of the paper.

\section{REFERENCES}

Agarwal S., Vailshery L.S., Jaganmohan, M., Nagendra H., 2013. Mapping Urban Tree Species Using Very High Resolution Satellite Imagery: Comparing Pixel-Based and Object-Based Approaches. In: ISPRS International Journal of Geo-Information, Vol 2, pp. 220-236.

Ananthakrishnan. R, Soman, M. K.,1988. The Onset Of The Southwest Monsoon Over Kerala:190 1-1980, In: Journal Of Climatology, VOL. 8. 283 -296. 
Baruth, B., Royer, A., Klisch, A., Genovese, G., 2008. The use of remote sensing within the mars crop yield monitoring system of the European commission. The International Archives of the Photogrammetry, Remote Sensing and Spatial Information Sciences. Vol. XXXVII. Part B8. Pp:936-939.

District Survey Report of Minor Minerals , Kozhikode District (2016). www.dmg.kerala.gov.in

HAPIS Portal: https://aps.dac.gov.in

Hebbar, R., Ravishankar, H. M., Trivedi, S., Subramoniam S.R., Raj, U., Dadhwal, V.K., 2014, Object Oriented Classification of High Resolution Data for Inventory of Horticultural Crops. In: The International Archives of Photogrammetry, Remote Sensing and Spatial Information Sciences, Vol XL-8, 2014.

Immitzer, M., Atzberger, C., Koukal, T., 2012. Tree Species Classification with Random Forest Using Very High Spatial Resolution 8-Band WorldView-2 Satellite Data. In: Remote Sensing, Vol-4, pp. 2661-2693.

Kannan, B., Ragunath K.P., Kumaraperumal, R., R. Jagadeeswaran R., and Krishnan R., 2017. Mapping of coconut growing areas in Tamil Nadu, India using remote sensing and GIS. In: Journal of Applied and Natural Science, Vol 9(2), pp. $771-773$

Mandal, D.M., Mandal, S., 2011. Coconut (Cocos nucifera L.: Arecaceae): In health promotion and disease prevention. In: Asia Pacific Journal of Tropical Medicine, pp. 241-247.

Mellor, A., Haywood, A., Jones, S., Wilkes, P., 2012. Forest Classification Using Random Forest with Multisource Remote
Sensing and Ancillary GIS Data. In: $16^{\text {th }}$ Australian Remote Sensing and Photogrammetry Conference Proceedings.

Parthasarthy, U., Das M.M., Kumaran P.M., Parthasarthy V.A.,2003, Identification of coconut plantation in Kasaragod district of Kerala with the help of satellite image. In: Indian Journal of Horticulture, Vol 60(4): 388-393, 200.

Rouse, J.W., Haas, R.H., Scheel, J.A. and Deering, D.W., 1974. Monitoring vegetation systems in the Great Plains. In: Proceedings, 3rd Earth Resource Technology Satellite (ERTS) Symposium, Vol-1, pp48-62.

Roxy, M.S., Sumithranand, V.B., Renuka, G., 2010, Variability of soil moisture and its relationship with surface albedo and soil thermal diffusivity at Astronomical Observatory, Thiruvananthapuram, south Kerala. In: Journel of Earth System Science, 119 , No. 4, pp. 507-517.

Sahay, B., Chakraborty, A., Chaudhary K.K., Laxman, B., Murthy, C.S., Rao P.V.N., 2017.Mapping Multiple Horticulture Crops using Object Oriented Classification Techniques. In: $38^{\text {th }}$ Asian Conference on Remote Sensing.

Santillan. J.R., M Santillan, M.M., Francisco. R., 2012. Using remote sensing to map the distribution of sago palms in northeastern Mindanao, Philippines: results based on Landsat ETM+ image analysis. In: The 33rd Asian Conference on remote Sensing.

Shaeb, B, Hareef. K, Joshi, A.K., Moharil, S.V., 2013. Surface reflectance retrieval from the high resolution multispectral satellite image using $6 \mathrm{~S}$ radiative transfer model, In: International Journal of Remote Sensing and GIS, Vol-2(3), pp. 130-137. 